\title{
0124 UNINTENTIONAL CHILDHOOD INJURY BURDEN, RISKS, AND OUTCOMES AT THE PAEDIATRIC EMERGENCY UNIT IN KAMPALA
}

M Mutto*, S Lawoko, C Nansamba, E Ovuga, L Svanström Correspondence: Pincer Group/ Karolinkska Institutet, Plot 46 Bukoto Street, Kamwokya, Kampala 72455, Uganda

10.1136/ip.2010.029215.124

Abstract Unintentional Childhood Injury burden, outcomes and risks are assessed in Kampala. Proportional incidence rates, percentages and injury odds are computed; risk trends are constructed. Five hundred and fifty-six childhood injuries were recorded between January and May 2008. Male: female ratio was 15:10. Parents transported most patients to hospital using mini-buses, private cars and motorcycles. Median injury location was $5 \mathrm{~km}$. Homes, roads, schools were lead locations. Play and daily living activities are commonest injury time activities. Falls, burns and traffic constitute $70.5 \%$ of injuries. Burns, open wounds, fractures are commonest. Motorcycles, buses and passenger cars caused most crashes. Play grounds, furniture, stairs and trees were commonest fall sources. Liquids, fires and hot objects cause most burn. $43.8 \%$ of cases were admitted. $30 \%$ were not disabled; $10 \%$, disabled; $1 \%$, fatal. Injury odds varied with age, place and cause. We failed to capture poisoning and drowning. Local paediatric injury priorities should include home, road and school safety. 